
\title{
9) Científic@
}

\section{INSTRUMENTOS INTERNACIONAIS DOS DIREITOS DOS POVOS INDÍGENAS: O DIREITO À CONSULTA PRÉVIA EFETIVA}

\author{
INTERNATIONAL INSTRUMENTS OF THE RIGHTS OF INDIGENOUS PEOPLES: THE RIGHT \\ TO PRIOR EFFECTIVE CONSULTATION
}

\author{
Fernanda Heloísa Macedo Soares ${ }^{1}$; Thiago Brito Steckelberg ${ }^{2}$; Vanderlei Luiz Weber ${ }^{3}$
}

${ }^{1}$ Mestre em Teoria do Direito (UNIVEM), Docente do Curso de Direito - FACEG

${ }^{2}$ Mestre em Ciências Ambientais; professor nos cursos de Direito e Enfermagem na Faceg; thiagosteck@ gmail.com

${ }^{3}$ Mestre em Direito Agrário; Professor do Curso de Direito da Faceg; vanderweber@ hotmail.com.

\section{Info}

Recebido: $20 / 05 / 2019$

Publicado: $31 / 05 / 2019$

DOI: 10.29247/2358-260X.2019v6i1.p159-172

ISSN: 2358-260X

Palavras-Chave
povos indígenas; instrumentos de
proteção internacional; consulta prévia
Keywords:
Indian people; instruments of international
protection; prior consultation

\section{Resumo}

O objetivo do presente estudo é discorrer sobre os instrumentos de proteção internacional aos povos indígenas como forma de garantir a autonomia e a cultura destes povos. Apesar de não proporcionarem a proteção ideal, os tratados e convenções internacionais constituem a mais importante ferramenta para a preservação da cultura e dos direitos dos povos indígenas, portanto, devem ser considerados e respeitados pelos Estados nacionais e ao mesmo tempo aperfeiçoados em seu alcance e abrangência. Inicialmente, o artigo trata do encontro histórico entre os europeus e os nativos americanos e a percepção destes povos no imaginário europeu e na visão antropológica. Posteriormente, abordou-se o histórica da proteção dos povos indígenas e por fim a concepção de pluralismo jurídico e sua relação com o direito à consulta prévia. Para a realização do presente estudo, além da consulta aos arquivos oficiais das Nações Unidas e de outras instituições internacionais e interestatais disponíveis em bancos de dados eletrônicos, buscou-se fundamentar com autores renomados na área da antropologia como Darcy Ribeiro e Gilberto Freyre, bem como juristas como Miguel Reale. Espera-se com este artigo despertar conscientização sobre a necessidade de se efetivar os instrumentos internacionais de proteção aos povos indígenas e proporcionar esclarecimentos sobre o tema e assim alertar sobre a importância de se preservar a diversidade cultural e a autonomia dos povos indígenas que tanto foi prejudicada pelo processo de assimilação pelos invasores europeus.

\footnotetext{
Abstract

The objective of this study is to discuss the instruments of international protection to indigenous peoples as a way of guaranteeing the autonomy and culture of these peoples. Although they do not provide the ideal protection, international treaties and conventions constitute the most important tool for the preservation of the culture and the rights of the indigenous peoples, therefore, they must be considered and respected by the national states and at the same time perfected in their scope and scope. Initially, the article deals with the historical encounter between Europeans and Native Americans and the perception of these peoples in the European imaginary and the anthropological vision. Subsequently, the history of the protection of indigenous peoples was discussed, and finally the concept of legal pluralism and its relation to the right to prior consultation. In order to carry out the present study, in addition to consulting the official archives of the United Nations and other international and inter-state institutions available in electronic databases, we sought to establish with renowned authors in the area of anthropology such as Darcy Ribeiro and Gilberto Freyre, as well as jurists like Miguel Reale. This article is expected to raise awareness about the need to implement international instruments for the protection of indigenous peoples and to provide clarification on the subject and thus to warn about the importance of preserving the cultural diversity and autonomy of indigenous peoples that has been so harmed by the process of assimilation by the European invaders.
} 


\section{INTRODUÇÃO}

A presente produção tem como objeto de pesquisa o levantamento cronológico do surgimento da política colonial genocida contra os povos indígenas, bem como da evolução histórica dos instrumentos jurídicos internacionais ligados à conquista e proteção dos direitos desses povos. Tal estudo se demonstra essencial na medida em que desde o advento da colonização das américas, os personagens do velho mundo ascenderam sobre as comunidades indígenas cometendo um extermínio físico e cultural destes.

Assim, os tratados e convenções internacionais surgem como uma tímida, mas importante ferramenta de proteção a direitos como a garantia da demarcação ou manutenção de seus territórios, da sua estrutura e organização política e social, da saúde, da cultura e do modelo de vida em sua integridade. Tais instrumentos servem, então, como um freio no processo de intervenção e destruição desses povos e suas culturas, regulamentando e limitando as possibilidades de interferência em seus territórios e sua organização vital.

No paralelo da apresentação dos instrumentos internacionais garantidores dos direitos indígenas, se desenvolverá a ideia de que a mais importante das conquistas foi o direito à consulta prévia, na medida em que foi criado para ouvir estas coletividades e por se apresentar como alternativa para, a partir da oitiva das comunidades tradicionais, configurar o direito democrático à participação, garantindo seus direitos ligados a sua cultura, costumes, crenças e organização de modo geral.

Como requer a própria Convenção 169/89 da OIT, o direito de consulta será livre, prévio e informado. São essas as bases que devem fundamentar os argumentos que ora se estruturam em favor do fundamental mecanismo de consulta prévia.

Por esse motivo, o direito de consulta e o direito de participação são dispostos como aqueles que possuem a energia e a originalidade, tanto teórica quanto prática, necessárias para, através das manifestações e produção de vivências próprias das comunidades indígenas, seguir sendo o esteio de resiliência e luta dos povos afetados.

\section{II - ENCONTRO DE MUNDOS, COLONIALISMO E ALTERIDADE}

Acerca da impossibilidade do descobrimento da América Latina, Américo Vespúcio informa em relato que [...] Encontrei no continente mais multiplicidades de povos e animais que em nossa Europa, ou na Ásia, ou mesmo na África. Os primeiros escritos relacionados aos povos indígenas, logo após o advento do processo de colonização dão conta, na verdade, de elogiar e enaltecer a humanidade, os costumes, a beleza, a saúde e a solidariedade dessas gentes, considerando que a vivência indígena estava vinculada à ideia de integração: homem, terra, animais, águas etc, não passavam de integrantes de uma só e mesma natureza.

Igualmente o olhar de Pero Vaz de Caminha, em 23 de abril de 1500, caminha nessa direção quando apresenta suas impressões 
relacionadas à maneira como demonstravam sua pacificidade: [...] vinham todos rijos para o batel $e$ Nicolau Coelho fez sinal que pusessem os arcos; e eles os puseram. Colombo, por sua vez escreve que [...] Acredito que não exista no mundo melhor gente e melhor terra. Tanto o é que, breve, os intelectuais europeus a compararam à ilha chamada Utopia, dos escritos de Thomas Morus, onde defendia que a virtude consiste em viver segundo a natureza (apud MARÉS, 1988, p. 28-30).

A descrição de escritores europeus nas obras que deixaram por legado histórico dão conta de informar que o índio era forte, bonito, saudável e que zelava generosamente do seu território. Que era livre, igual, solidário, bem alimentado, generoso; possuía tudo o que era necessário para sobreviver e para reproduzir sua vida e sua cultura; sua fauna e flora eram ricas; e a diversidade de suas manifestações, fantástica. A tal ponto se encantou com o que experimentou por estas terras o colonizador que a maioria dos estrangeiros afirmava que era melhor se unir ao indígena selvagem do que se aliar aos europeus destrutivos, exploradores de riquezas alheias, egoístas, interesseiros, exterminadores e etnocidas.

Como consequência, reconheciam esses estrangeiros que só se completaram como seres humanos a partir da 'descoberta' e contato com os povos latino-americanos. Sua visão e sua vida foram provocadas a se modificar e temas como Deus, verdade, liberdade, superioridade, igualdade foram postos em questão, vez que o europeu vivia em constantes conflitos entre si e com países vizinhos. Fome, concentração de riqueza e poder, assassinatos por interesse faziam parte do seu diaa-dia. Com o contato, ele teria se posto a possibilidade de repensar esse modo de ser a fim de operar sua 'construção' humanizadora.

Politicamente, para o frade dominicano espanhol e defensor dos indígenas Bartolomé de Las Casas, todos os reinos da América eram possuídos da mesma pleníssima potestade dos reinos de Europa, mas nem Portugal nem Espanha reconheceram a "plenissima potestade' dos reis de coroa de penas, nem seus dominios como território independente. E a posição jurídicoteológica do Frei Las Casas era a de que não se deveria interferir na vida, organização social, direito e território destes povos. Além disso, afirmava que a justiça e a disposição divinas e o direito natural e das gentes são pressupostos anteriores ao conbecimento, exatamente por isso, universais [...] (MARÉS, 1988, p. 48).

Todavia, apesar dos relatos e declarações do colonizador, isto não o impediu de ser contraditório na sua prática, ao usar os povos indígenas para lhe servir de escravos e dizimá-los. Contradição esta que desconsiderou qualquer projeto das novas alteridades 'descobertas'. De modo que não houve qualquer reconhecimento da organização política, econômica, social e jurídica destes povos. Ao contrário, desde logo o modelo que regulou a relação entre os povos indígenas e a sociedade ocidental colonizadora, se demonstrou opressor, escravagista e homogeneizante.

Darcy Ribeiro (2010, p. 23), importante antropólogo indigenista, em sua obra Meus índios, minha gente, escreve acerca da tragédia que recaiu sobre as comunidades indígenas: Gente que sofria a 
dor suprema de ser indio num mundo hostil, mas ainda assim guardava no peito um louco orgulho de si mesmos como indios. Gente muito mais capaz que nós de compor existências livres e solidárias.

Dessa forma, o europeu se impôs sobre os povos indígenas desde a sua chegada e seu olhar de superioridade os 'civilizou', os 'moralizou', colocou-lhes nome e os tornou sua propriedade (porque nomeá-los era como apossar-se deles, escravizá-los) e, ainda, delimitou os seus territórios. Como resultado dessa ação, o 'olhar' do europeu sobre o indígena o diminuiu, o dividiu, o limitou, o classificou, o descriminou, o alienou e, em expressiva parte, fez desaparecer seu modus vivendi. A única verdade reconhecida como legítima era a dita pelo europeu, apesar de, na maioria das vezes não ter nenhuma relação com a realidade.

Diante dessas percepções e ações paradoxais se reforça a necessidade de se repensar essa trajetória, aprofundando, no espaço que este trabalho permite, o debate acerca do reconhecimento da diversidade das comunidades tradicionais (dos povos indígenas, nesse caso), por meio de instrumentos internacionais de exigente conquista, como o caso da Convenção 169/89, da OIT, com ênfase no papel do direito de consulta prévia, bem como a evolução da temática do pluralismo jurídico e da construção de um possível estado plurinacional, que poderia garantir maior efetividade aos direitos dessas comunidades. É o que se fará nos tópicos que seguem.

III - HISTÓRICO DAS CONQUISTAS DE PROTEÇÃO INTERNACIONAL DOS DIREITOS INDÍGENAS
Dado o surgimento da Organização das Nações Unidas (ONU), fundada em 1945 para substituir a frustrada Liga das Nações, em ato seguinte, a partir do ano de 1949, passou ao interesse de investigar a situação das comunidades indígenas existentes no continente americano. Para tanto, foi criado um grupo de estudos por meio de Assembleia Geral que, dada a falta de apoio do imperialismo norte americano, não alcançou seus objetivos.

Pari passu, se tem que a Declaração Universal dos Direitos Humanos de 1948, primeiro documento internacional a ter proclamado direitos civis, políticos, econômicos, sociais e culturais para toda a humanidade, teria contemplado os povos indígenas nesta legislação, mesmo que tratando de uma garantia formal. Eis a transcrição do art. $2^{\circ} \mathrm{da}$

Declaração:

Art. 2.

1. Todo ser humano tem capacidade para gozar os direitos e as liberdades estabelecidos nesta Declaração, sem distinção de qualquer espécie, seja de raça, cor, sexo, idioma, religião, opinião política ou de outra natureza, origem nacional ou social, riqueza, nascimento, ou qualquer outra condição.

2. Não será também feita nenhuma distinção fundada na condição política, jurídica ou internacional do país ou território a que pertença uma pessoa, quer se trate de um território independente, sob tutela, sem governo próprio, quer sujeito a qualquer outra limitação de soberania.

Se passou outra década para se criar convenção que mencionasse explicitamente as comunidades indígenas. Trata-se da Convenção n. 107, de 10 de junho de 1957, que se ocupou com a 
Proteção e a Integração das Populações Indígenas e Outras Populações Tribais e Semitribais, especialmente no que se refere à regulamentação das relações de trabalho.

Apesar do seu viés integracionista/assimilacionista e de que vários de seus institutos já se encontram desatualizados para os tempos hodiernos, tal Convenção teve um importante papel de proteção dos direitos indígenas e um marco referencial no momento da sua criação, enquanto regulamentadora das relações de trabalho indígenas por longo período, vez que a Convenção em análise foi ratificada pelo Brasil em 1965 e vigorou de 1966 até 2003.

A principal crítica ao Documento foi a utilização da expressão "nível menos desenvolvido" ao se referir aos nativos brasileiros, o que teve como consequência a não efetividade no trato da preservação das culturas indígenas, como seu artesanato, suas manifestações artísticas na dança e na música e seu modo de vida peculiar.

Tal crítica foi acompanhada pela do enfoque integracionista dos povos indígenas à comunidade nacional dado à Convenção, o que fez com que ela passasse por processo de revisão a partir dos anos 80 e fosse substituída por um novo documento legal.

Trata-se da Convenção 169/1989 da Organização Internacional do Trabalho (OIT), que apesar de contar com explícito teor direcionado aos povos indígenas, somente foi ratificada pelo Congresso Nacional brasileiro no ano de 2002, passando a vigorar no ano seguinte.
A temática central da Convenção é a de que há grupos portadores de identidades específicas e que cabe ao Direito assegurar-lhes 0 controle de suas próprias instituições e formas de vida e seu desenvolvimento econômico, e manter e fortalecer suas identidades, línguas e religiões, dentro do âmbito dos Estados onde moram (OIT, Convenção 169, preâmbulo). Assim, [...] a defesa da diversidade cultural passa a ser, para os Estados nacionais, um imperativo ético, inseparável do respeito à dignidade da pessoa bumana (DECLARAÇÃO UNIVERSAL SOBRE A DIVERSIDADE CULTURAL, art. $4^{\circ}$ ).

Tal Convenção é fundamental também porque explicita que o governo deve assegurar aos povos indígenas os mesmos direitos a que fazem jus os demais estratos sociais. Em determinada parte do texto há a chamada por ações positivas ou afirmativas por parte do Estado a fim de garantir que as comunidades nativas, além de deter a titularidade de seus direitos, possam também exercê-los. Para ilustrar, no art. 30 do documento encontramos a informação de que

Art. 30
1. Os governos deverão adotar
medidas de acordo com as
tradições e culturas dos povos
interessados, a fim de lhes dar a
conhecer seus direitos e
obrigações especialmente no
referente ao trabalho e as
possibilidades econômicas, as
questões de educação e saúde,
aos serviços sociais e aos
direitos derivados da presente
Convenção.

A Carta traz um conjunto de direitos aos agrupamentos humanos, nesse caso aos povos indígenas, que possuem condições sociais, econômicas e culturais específicas e que, portanto, se distinguem de outros setores da coletividade 
nacional. Assim, a Convenção, vinculada aos ditames da Constituição Federal de 1988, se transforma no primeiro instrumento internacional a garantir o respeito as tradições indígenas, eliminando de vez o pensamento assimilacionista nacional, tão defendido em legislações anteriores, vez que agora se garante o direito dos indígenas de permanecer da forma como é próprio da sua organização social.

Como já informado acima, o Brasil levou um período de 13 anos para aprovar a Convenção. A motivação para a demora estaria ligada às palavras "povos e território". Todavia, quando o instrumento se refere a povos, não o faz no sentido político a fim de legitimar a independência e autodeterminação e se transformar em nação, mas, simplesmente para atender o sentido de comunidade histórica. Para Hartmut-Emannuel Kayser (2010, p. 337)

A Convenção 169 utiliza, [...] o termo "povos" indígenas. Isto se baseia na concepção de que a utilização do conceito de "povos" é necessária para o fortalecimento do reconhecimento do direito destes grupos à sua identidade, e como um aspecto fundamental da orientação modificada com respeito à maior observância de suas culturas e modos de vida.

Voltar-se-á à Convenção 169 quando se tratar da temática da consulta prévia, direito apresentado e protegido pela referida carta e que, se aplicado, resulta na guarida de um sem número de garantias aos povos indígenas e às comunidades tribais em geral.

Outro documento que representa ampliação das conquistas indígenas é o Pacto
Internacional sobre os Direitos Civis e Políticos, que foi aprovado no ano de 1966 pela Assembleia Geral das Nações Unidas (AGNU) e aberto à adesão dos Estados signatários da ONU, mas que somente foi ratificado no ano de 1992.

O Pacto não possui normas expressamente direcionadas aos povos indígenas, todavia, os direitos nele informados podem ser aplicados em favor destas comunidades, vez que há em seus artigos norma que abre interpretação em favor da tutela das populações em debate.

Trata-se especialmente do art. 27 que garante a proteção das pessoas que são classificadas como integrantes de minorias, onde os povos indígenas se encontram incluídos. É o que diz o conteúdo do mencionado dispositivo:

Nos Estados em que haja
minorias étnicas, religiosas ou
linguísticas, as pessoas
pertencentes a essas minorias
não poderão ser privadas do
direito de ter, conjuntamente
com outros membros do seu
grupo, sua própria vida
cultural, de professar e praticar
sua religião e usar sua própria
língua.

Disso se depreende que aos povos indígenas estão resguardados, sem qualquer restrição, o direito de manter, cultivar e desenvolver sua cultura, religião e língua, apesar do art. 27 do PIDCP não haver precisado o conceito de minoria. O que, em seguida, foi realizado pelo Direito Internacional Público, que o fez para dar efetividade ao instituto previsto no Pacto. Dessa forma, afirmou que

existe uma minoria [...] quando se trata de um grupo, que em um período determinado de tempo, é numericamente menor que o restante $\mathrm{da}$ população de um Estado, e que 
não se encontra em posição dominante. Ao mesmo tempo, os membros desse grupo devem apresentar características étnicas, religiosas ou linguísticas que os diferenciem do restante da população, para que possam ser reconhecidas por um sentimento de solidariedade em relação a sua cultura, tradição, religião ou língua (KAYSER, 2010, p. 329).

Além da sua sensível diferença em relação à cultura branca, as próprias etnias indígenas se diferenciam umas das outras de modo que o Pacto se torna uma forma de garantir essa diversidade e de preservar modos de vida próprios da sua tradição e das instituições políticas, econômicas, culturais e espirituais que serão repassadas para as futuras gerações com o objetivo de continuidade de tal riqueza histórico-cultural.

No ano de 1978 tem ocorrência outro evento de relevância no cenário internacional. Trata-se da assinatura, pela Organização dos Estados Americanos (OEA), da Convenção Americana de Direitos Humanos, ou Pacto de San Jose de Costa Rica, com o objetivo de consolidar regimes de liberdade pessoal e de instituições democráticas.

Aos povos indígenas ficam resguardados os direitos contidos no Pacto, mesmo que não direcionados diretamente a eles. Como integrantes da população brasileira, país que ratificou a Convenção apenas em 1992, as comunidades indígenas tem seus direitos humanos protegidos, sem discriminação ou desigualdade.

Assim se lê no art. $1^{\circ}$, I do Pacto de San Jose de Costa Rica:

Os Estados-partes nesta Convenção comprometem-se a respeitar os direitos e liberdades nela reconhecidos e a garantir seu livre e pleno exercício a toda pessoa que esteja sujeita à sua jurisdição, sem discriminação alguma, por motivo de raça, cor, sexo, idioma, religião, opiniões política ou de qualquer outra natureza, origem nacional ou social, posição econômica, nascimento ou qualquer outra condição social.

Para Luiz Fernando Villares (2009, p. 50), o Pacto registra a diferença de ter nele previsto $a$ criação de instituições internacionais de acompanhamento de sua aplicação e cumprimento, (como) a Comissão Interamericana de Direitos Humanos e a Corte Interamericana de Direitos Humanos.

A Declaração das Nações Unidas sobre os Direitos dos Povos Indígenas é um importante instrumento que emerge no cenário internacional após aproximadamente 20 anos de estudos realizados por integrantes das próprias comunidades indígenas e grupos a eles alinhados. A Declaração, adotada pela Assembleia Geral da ONU em 13 de setembro de 2007, estabelece diretrizes universais de padrões mínimos de sobrevivência para a dignidade e o bem-estar dos povos indígenas do mundo.

Nessa direção, diversos países avançaram em reconhecer formalmente os direitos nela previstos, mas, frequentemente, eles continuam a enfrentar discriminação, marginalização e grandes desafios na garantia de seus direitos básicos.

40 entidades do Sistema ONU e outras organizações internacionais, em comunicado conjunto emitido para o Dia Internacional dos Povos Indígenas, em 09 de agosto de 2017, dez anos após assinatura do referido documento 
avaliaram que, ao mesmo tempo que os povos indígenas realizaram significativos avanços em defender seus direitos nos fóruns internacionais e regionais, a implementação da Declaração é obstruída pela persistente vulnerabilidade e exclusão, particularmente de mulheres, crianças, jovens e pessoas indigenas com deficiência.

A Declaração das Nações Unidas sobre os Direitos dos Povos Indígenas é o instrumento internacional mais abrangente sobre os direitos coletivos dos povos indígenas, incluindo os direitos à autodeterminação, as terras tradicionais e a sua cultura. No entanto, tal declaração, assim como as demais Declarações genéricas da ONU, como a Declaração dos Direitos Humanos, necessitam de complementação regional e de outros instrumentos mais vinculantes para se tornarem efetivos compromissos a serem respeitados pelos governos e no âmbito interno dos Estados.

IV - IDEIAS ACERCA DO PLURALISMO JURÍDICO E SUA RELAÇÃO COM O DIREITO À CONSULTA PRÉVIA

Como já dito anteriormente, apenas uma releitura dos fenômenos jurídicos, considerados como um elemento inserido e interligado à complexidade da teia da vida pode proporcionar uma nova forma de atuação do Direito, como real instrumento de realização de bem-estar social e, principalmente, de bem-estar humano. O que no pensamento teórico de Boaventura de Sousa Santos, na sua obra "A Crítica da Razão Indolente", representa sua noção paradigmática centrada na ideia de construção de um conbecimento prudente para uma vida decente, propondo que, para executá-la, se realize a revolução científica com ocorrência na sociedade que, por sua vez, é revolucionada por esta ciência que será norteada pelo paradigma científico do 'conhecimento prudente' e pelo paradigma social da 'vida decente' (SANTOS, 2000, p. 74).

No pensar de Ronald Dworkin, a obra "Uma Questão de Princípio" é a referência enquanto o fato de os juristas, em suas decisões, se perguntarem acerca de se querem utilizar como parâmetro princípios econômicos ou princípios políticos para chegar a consecução da justiça (DWORKIN, 2000). Para John Rawls, o paradigma jurídico se diagnostica na 'realização' dos princípios da igualdade e da diferença, afirmando que [...] para se aplicar a noção de justiça processual pura à distribuição, é necessário estabelecer-se um sistema justo de instituições e administrá-lo de forma imparcial (RAWLS, 2003, p. 86-87). Para Fritjof Capra, em especial na sua produção em O Ponto de Mutação: a ciência, a sociedade e a cultura emergente, a proposta de uma "ecologia profunda" norteada por uma visão holística da vida, onde se privilegiaria a interconexão de relações com base na lógica de estrutura atômica (CAPRA, 2001).

Já a proposta que Joaquim Herrera Flores (2009) apresenta é a do relativismo relacional que provoca a possibilidade de nos 'obrigarmos' a considerar como possível qualquer outra forma de manifestação humana e cultural diversa daquela já padronizada, quer nos agrade, quer não. Para o pensador da Política da Libertação, Enrique Dussel, o papel constitutivo de um Estado acompanha o dever de contemplar e tratar todos 
os seus cidadãos como iguais, enquanto provocador da participação e reconhecedor de direitos e diferenças. Assim, os anteriores, os esquecidos, os distantes, as minorias, os excluídos, ao invés de terem seus direitos escolhidos pelo Estado, deveriam ser chamados ao papel democrático de escolher e organizar-se por si próprios (DUSSEL, 2011).

Essas assertivas implicam em que, ao se retomar a temática do pluralismo jurídico como referencial de estudo e fundamentação, deve-se superar o modelo de cultura sócio-política que se identifica à tradição tanto do pluralismo orgânicocorporativista, como do neoliberal-capitalista, dada a crise do modelo jurídico liberal-individualista, que não mais encontra guarida deste nas suas reclamações político-sociais. Por isso mesmo, se torna necessário determinar um novo pluralismo que emane da contradição do modelo de produção atual, bem como do processo dialético próprio dos atores da história recente, considerando-se suas necessidades individuais e coletivas (WOLKMER, 2001).

Nessa direção, observa-se que é acentuado o desencontro entre a 'racionalidade formal' do Estado e o que vive na realidade da 'racionalidade material', processo que é resultado de um conjunto de lutas numa sociedade desigual, notadamente dividida pelas diferentes expectativas, fazendo com que, o que seja segurança para poucos, se traduza em violência para muitos.

Com base nisso, a proposta que Wolkmer apresenta se configura em torno de um pluralismo político e jurídico de base comunitárioparticipativa, pretendendo demonstrar que,

[...] tanto no nível teórico quanto prático, que é logicamente possível, para além dos meios de regulamentação instituídos e agora dominantes (normas costumeiras, judiciais e legais), a existência concorrente e paralela de expressões normativas-estatais, não derivadas dos canais oficiais e formalizadas, mas emergentes das interações e das flutuações de um processo de auto-regulação em constante recriação (WOLKMER, 2001, p. XIX).

Esse seria o modelo ideal para a solução da crise, das constantes injustiças cometidas, especialmente contra sujeitos coletivos, e da flagrante ineficácia da legalidade monista, sustentada e dependente do aparato hegemônico do Estado. Esse processo teria como finalidade gradual e alternativa a construção de um novo paradigma social de produção de normas.

Optando por este modelo de pluralismo (o de base comunitário-participativa) estaríamos nos afastando de fórmulas plurais anteriores, vez que este não tem vínculo com a representação individual no mundo social, mas representa a síntese dos interesses da vida real, tanto individuais quanto coletivos. Projeto este, portanto, contrário ao pluralismo liberal-burguês, de viés nitidamente elitista, conservador e selvagem, privilegiador dos interesses de segmentos exclusivistas e de grupos minoritários detentores do poder de decisão, desconsiderando-se as necessidades da vida comunitária (WOLKMER, 2001).

Essa ideia de um pluralismo que institui um direito comunitário criaria, por corolário, uma 
cultura jurídica pluralista, descentralizada e solidária, não a partir da metafísica, mas considerando um 'sujeito histórico-em-relação' e de uma outra forma de ver o mundo e os valores (WOLKMER, 2001, p. XX). O novo modelo deverá, progressivamente superar conflitos de classes e erradicar a opressão, a espoliação, o sofrimento e a injustiça.

Ainda segundo o autor,

[...] o novo pluralismo jurídico como referencial cultural de ordenação partilhada, constróise por meio de condições 'materiais' e 'formais' que englobam a legitimidade de novos sujeitos coletivos, a implementação de um sistema justo de necessidades, a democratização

descentralização de um espaço público participativo, o desenvolvimento pedagógico para uma ética concreta da alteridade e a consolidação de processos conducentes a uma racionalidade emancipatória (WOLKMER, 2001, p. XX$\mathrm{XXI})$.

Dessa forma, trata-se de uma perspectiva descentralizadora e antidogmática que pleiteia a supremacia de fundamentos ético-político-sociológicos sobre critérios tecno-formais positivistas (WOLKMER, 2001, p. 7).

Ante o exposto, precisas são as palavras de Catusso, ao sintetizar que

[...] o que se busca é um novo paradigma para solução dos conflitos que emergem da vida comunitária, com uma regulação que supere o já inadequado modelo vigente, incapaz de solucionar eficazmente as demandas populares. É nesse espaço de insatisfação com a ordem vigente que surgem propostas para repensar sociologicamente novas normas de referência e legitimação para o jurídico, que ofereçam prioridade às necessidades mais imediatas da sociedade civil e envolvam um projeto cultural emancipador. As propostas de pluralismo jurídico aparecem nesse contexto, como horizontes de uma nova legalidade, capaz de captar as práticas reais da população, aproximando a produção do direito da sociedade civil (CATUSSO, 2007, p. 121).

Já para José Geraldo de Souza Júnior, [...] estas sugestões reforçam a concep̧̧ão do pluralismo jurídico, reposicionada num contexto paradigmático em condições de assimilar as transições no modo de produção do Direito, em investigadores como Boaventura de Sousa Santos (SOUSA JÚNIOR, 2002, p. 261).

Segundo o autor, a essência do Direito achado na rua também acaba por valorizar e contribuir com o pluralismo jurídico, podendo-se afirmar a existência de uma possível analogia, vez que ambos os temas trazem à baila reflexões tanto quanto ao monopólio da produção normativa pelo Estado quanto da emanação de 'novos' sujeitos coletivos que assumem posição destacada no contexto atual e, nessa posição, se destacariam as comunidades indígenas.

Quanto ao pluralismo jurídico em si, este é importante para que se compreenda a necessidade de considerar os vários grupos, movimentos e as diversas posições por eles defendidas na esfera jurídica. E, o Direito deve buscar na sociedade seu sentido, uma vez que desvinculado dela ele a põe em xeque: se se busca um direito realmente democrático, ele deve sofrer a influência da própria sociedade civil (a quem o direito deve prestar contas) (CARVALHO, 1997, p. 17).

Pelo que já foi apontado, fica claro que a (nova) concepção de Direito, aqui apresentada, 
passa a ser o de ferramenta fundamental para a transformação da sociedade e que, para tal se efetivar, é imprescindível a tomada de consciência e uma postura teórico-prática otimizadora dessa potencialidade. Nesse sentido, disseminar o conhecimento, intensificar o debate jurídico e abrir os espaços do Direito para a participação popular são requisitos fundamentais para sua efetivação em favor da sociedade no seu todo.

E um importante instrumento para alcançar esse pleito é a Convenção sobre os Povos Indígenas e Tribais (Convenção 169 da OIT, 1989 - já mencionada anteriormente), que abre caminho para que os povos indígenas pressionem os governos a implementar seus direitos e mobilizem novas pressões internacionais. Uma das formas de garantir este implemento é o comando do art. $2^{\circ}$ da Convenção que informa que Os governos deverão assumir a responsabilidade de desenvolver, com a participação dos povos interessados, uma ação coordenada e sistemática com vistas a proteger os direitos desses povos e garantir o respeito pela sua integridade.

Enquanto isso, o art. $6^{\circ}$ da Convenção tratará do direito à consulta como maneira de fortalecer a participação livre, prévia e informada, enquanto se adotem procedimentos apropriados, mediados pelas associações representativas, quando não for possível participar diretamente.

Dada a relevância do art. $6^{\circ}$, apresenta-se a redação em inteiro teor:

Art. 6.

1. Ao aplicar as disposições da presente Convenção, os governos deverão:

a) consultar os povos interessados, mediante procedimentos apropriados e, particularmente, através de suas instituições representativas, cada vez que sejam previstas medidas legislativas ou administrativas suscetíveis de afetá-los diretamente;

b) estabelecer os meios através dos quais os povos interessados possam participar livremente, pelo menos na mesma medida que outros setores da população e em todos os níveis, na adoção de decisões em instituições efetivas ou organismos administrativos e de outra natureza responsáveis pelas políticas e programas que lhes sejam concernentes;

c) estabelecer os meios para o pleno desenvolvimento das instituições e iniciativas dos povos e, nos casos apropriados, fornecer os recursos necessários para esse fim.

2. As consultas realizadas na aplicação desta Convenção deverão ser efetuadas com boa fé e de maneira apropriada às circunstâncias, com o objetivo de se chegar a um acordo e conseguir o consentimento acerca das medidas propostas.

Como exemplo, temos a Estrategia Española de Cooperación con los Pueblos Indígenas, que tem como objetivo algo que parte da especificidade dessas culturas, tão diferente em suas concepções de desenvolvimento com relação a visão ocidental, que é o de apoiar todos seus processos de autodesenvolvimento sustentável, que permitam sua participação nos processos de tomada de decisão quando lhes afetem diretamente, e que sejam implementados por eles mesmos, partindo de suas próprias culturas e da relação de identificação com o meio ambiente que ocupam (GARCÍAROMEU; LÓPEZ; HUERTAS, 1998).

De tal forma isso ocorre que o modelo possui dois eixos centrais de orientação: a) a participação dos indigenas em foros nacionais $e$ 
internacionais, integração nas políticas de desenvolvimento de seus países bem como de suas próprias estratégias e projetos; b) programas e projetos de capacitação, formação e educação, com especial atenção a educação bilíngüe (GARCÍAROMEU; LÓPEZ; HUERTAS, 1998, p. 6 tradução livre).

Tal proposta demonstra que fomenta e cumpre com o projeto de auto-desenvolvimento e de participação indígena, marcando um novo caminho intercultural a ser seguido em modelos paralelos e em atuações futuras, como o fez o II Foro Internacional Indígena sobre Biodiversidade e a Oficina do CBD (da III Conferencia das Partes do Convenio de Biodiversidade).

Em contrapartida, partindo da ideia de Boaventura de Souza Santos de construção de um "conhecimento prudente para uma vida decente", se pergunta se é possível sustentar a hipótese da construção de um Estado Plurinacional, que considere a participação democrático-comunitária e o desenvolvimento de um pluralismo jurídico paraestatal, onde costumes, tradições e modelos político-econômico-sociais sejam reconhecidos como próprios dos povos indígenas e demais comunidades tradicionais, vez que necessários para sua sobrevivência física e cultural?

Raquel Yrigoyen Fajardo (2013) ao se perguntar quais são os direitos que o Convênio 169/89 estabelece, encontra resposta no direito à livre determinação, que estaria na base para definir as prioridades das comunidades indígenas por elas mesmas, controlando seu modelo de desenvolvimento e, especialmente, participando nas decisões estatais com destaque para aquelas que as afetam diretamente.
Segundo Diego García-Sayán, membro da Corte Interamericana de Direitos Humanos (2013), hoje em dia as comunidades tradicionais, e os povos indígenas em particular, são atores cuja participação em um congresso democrático não se limita ao exercício do direito ao voto, senão ao direito de participação.

E, assim, por ser um direito, necessita ser organizado de maneira eficiente pelo Estado, de modo que as normas e decisões administrativas que afetam os povos indígenas estejam envolvidas por um processo de interação. $\mathrm{O}$ que por ora ocorre num ambiente de reconhecimento onde existe o Estado, por se tratar de um assunto entre iguais, apesar da precária relação de ainda ser a autoridade estatal a tomadora de decisões.

\section{V - CONCLUSÃO}

Para que se realize o fechamento do presente trabalho, contamos com a orientação de César Rodríguez Garavito e Natalia Orduz Salinas (2012), que nos dizem que desde o advento da Convenção 169 da OIT e da Declaração das Nações Unidas sobre o Direito dos Povos Indígenas deve se construir um consenso acerca da consulta prévia.

O que ocorre até o momento, todavia, é que tal normativa raramente é efetivada na prática. No caso brasileiro, país onde o texto foi tardiamente aprovado por meio do Decreto Legislativo $\mathrm{n}^{\mathrm{o}} 143$, de 20 de junho de 2002, e promulgado para poder operar com eficácia por meio do Decreto no 5.051, de 19 de abril de 2004, já distam 14 anos de lá para cá e a Convenção tem registrado rara efetividade. O que leva a questão: 
quem pagará por esse dívida da falta da oitiva livre, prévia e informada dos povos indígenas para qualquer temática que lhes diga respeito?

Há, inclusive, uma abundância de casos nos quais se desconhece os requisitos que definem a consulta, como também são muitos os casos em que se vê a completa ausência desta prática quando da produção de normas que afetam as populações indígenas. Por outro lado, não há segurança quanto ao significado prático e há incertezas que se evidenciam especialmente nas consultas sobre projetos econômicos específicos.

Assim, que passos deve incluir a consulta? Com quem se deve consultar? Em que língua? Quais efeitos tem a consulta? Se deve consultar antes da apresentação do projeto ao Congresso, ou depois que o Congresso já o tenha aprovado, mas antes que o Executivo o sancione? No primeiro caso, o que acontece se o texto consultado sofre modificações durante o debate parlamentar? E, no segundo caso, o que acontece se da consulta surgem modificações no projeto já aproado pelo Congresso? Estas e outras questões ainda não encontram assertivas seguras acerca das mesmas, valendo a pena manter o debate acerca delas.

O certo é que, de fato, dentro das questões e situações apresentadas, a consulta se faz obrigatória. E, cada vez mais seus procedimentos precisam ser efetivados e aplicados a cada realidade conforme as particularidades e necessidades de cada comunidade.

\section{V - REFERÊNCIAS}

CAMPILONGO, Celso Fernandes e FARIA, José Eduardo. A Sociologia Jurídica no Brasil, s/d, p. 38.

CAPRA, Fritjof. O Ponto de Mutação - A Ciência, a Sociedade e a Cultura emergente. Tradução Álvaro Cabral. São Paulo: Cultrix, 2001.

CATUSSO, Joseane. Pluralismo Jurídico: um novo paradigma para se pensar o fenômeno jurídico. Revista Eletrônica do CEJUR, Curitiba, a. 2, vol. 1, n. 2, ago./dez., 2007.

FREIRE, Paulo. Educaáão como prática da liberdade. 31. ed. Rio de Janeiro: Paz e Terra, 2008.

GARAVITO, César Rodríguez; SALINAS, Natalia Orduz. La Consulta Previa: Dilemas Y Soluciones. Lecciones del proceso de construcción del decreto de reparación y restitución de tierras para pueblos indígenas en Colombia. DeJusticia. Bogotá: Ediciones Antropos, junio de 2012.

GARCÍA-SAYÁN, Diego. Pluralismo Juridico, Jurisdicción Indígena y Derechos Humanos en la región andina. Publicado en 30 de julho de 2013. Disponível em https://www.youtube.com/watch?v=t7P2

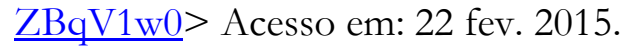

REALE, Miguel. Pluralismo e Liberdade. São Paulo: Saraiva, 1963.

SANTOS, Boaventura de Sousa. Poderá o Direito ser emancipatório? Florianópolis: Fundação Boiteux, 2007.

SANTOS, Boaventura de Sousa. A formação dos magistrados e a cultura jurídica. In: _. Para uma revolução democrática da justiça. São Paulo: Cortez, 2007. p. 66-78. (Coleção Questões da Nossa Época, v.134).

SANTOS, Boaventura de Sousa. Notas sobre a História Jurídico-Social de Pasárgada. In: FALCÃO, J.; SOUTO, C. (Org.). Sociologia e Direito. 2. ed. São Paulo: Pioneira Thomson, 2002. p.87-95.

SOUSA JÚNIOR, José Geraldo de. O direito achado na rua: concepção e prática. Revista bumanidades. Brasília, n.4, vol.8, p.494-497, jun. 1992. p. 494. 
SOUSA JÚNIOR, José Geraldo de. Direito como liberdade: $\mathrm{O}$ Direito Achado na Rua (Experiências populares Emancipatórias de Criação do Direito). 2008. 338 f. Tese de doutoramento - Universidade de Brasília, Brasília, 2008. p. 05.

WOLKMER, Antonio Carlos. Pluralismo Jurídico Fundamentos de uma nova cultura no Direito. 2. ed. São Paulo: Alfa-Omega, 2001.

WOLKMER, Antonio Carlos; VERAS NETO, Francisco Q.; RIXA, Ivone M.
Organizadores. Pluralismo Jurídico: os novos caminhos da contemporaneidade. São Paulo: Saraiva, 2010.

WOLKMER, Antonio Carlos. Pluralismo Jurídico: Nuevo marco emancipatorio en América Latina, en TORRE RANGEL, Jesús Antonio (coord.). Pluralismo Jurídico, teoría y experiencias, San Luis Potosí, Facultad de Derecho de la Universidad Autónoma de San Luis Potosí y Centro de Estudios Jurídicos y Sociales P. Enrique Gutiérrez. 